\section{Endoscopic vacuum therapy for acute esophageal perforation following pneumatic dilation}

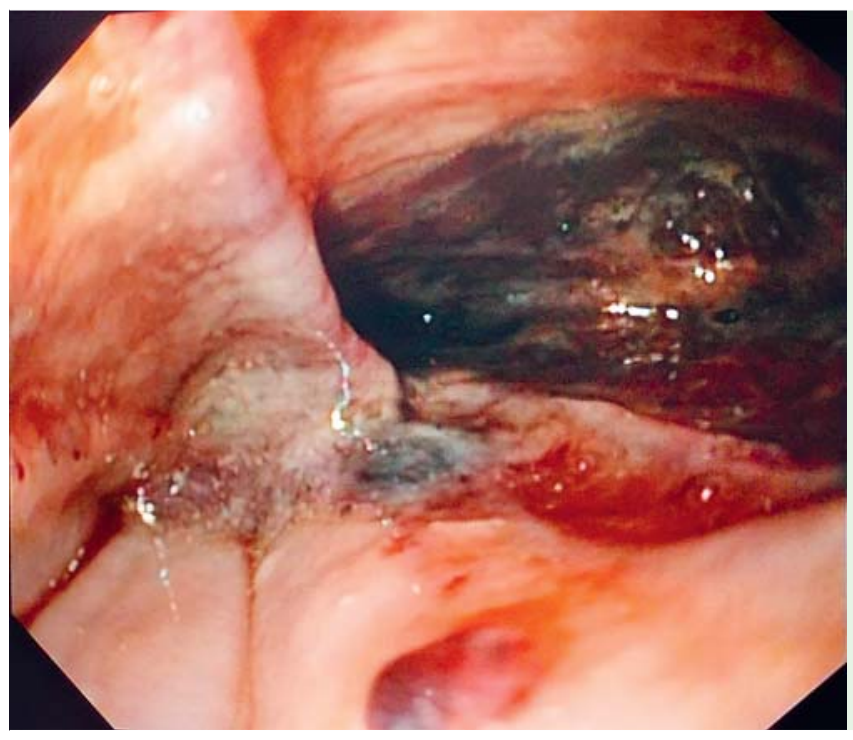

Fig. 1 Large rupture of the thoracic esophagus.
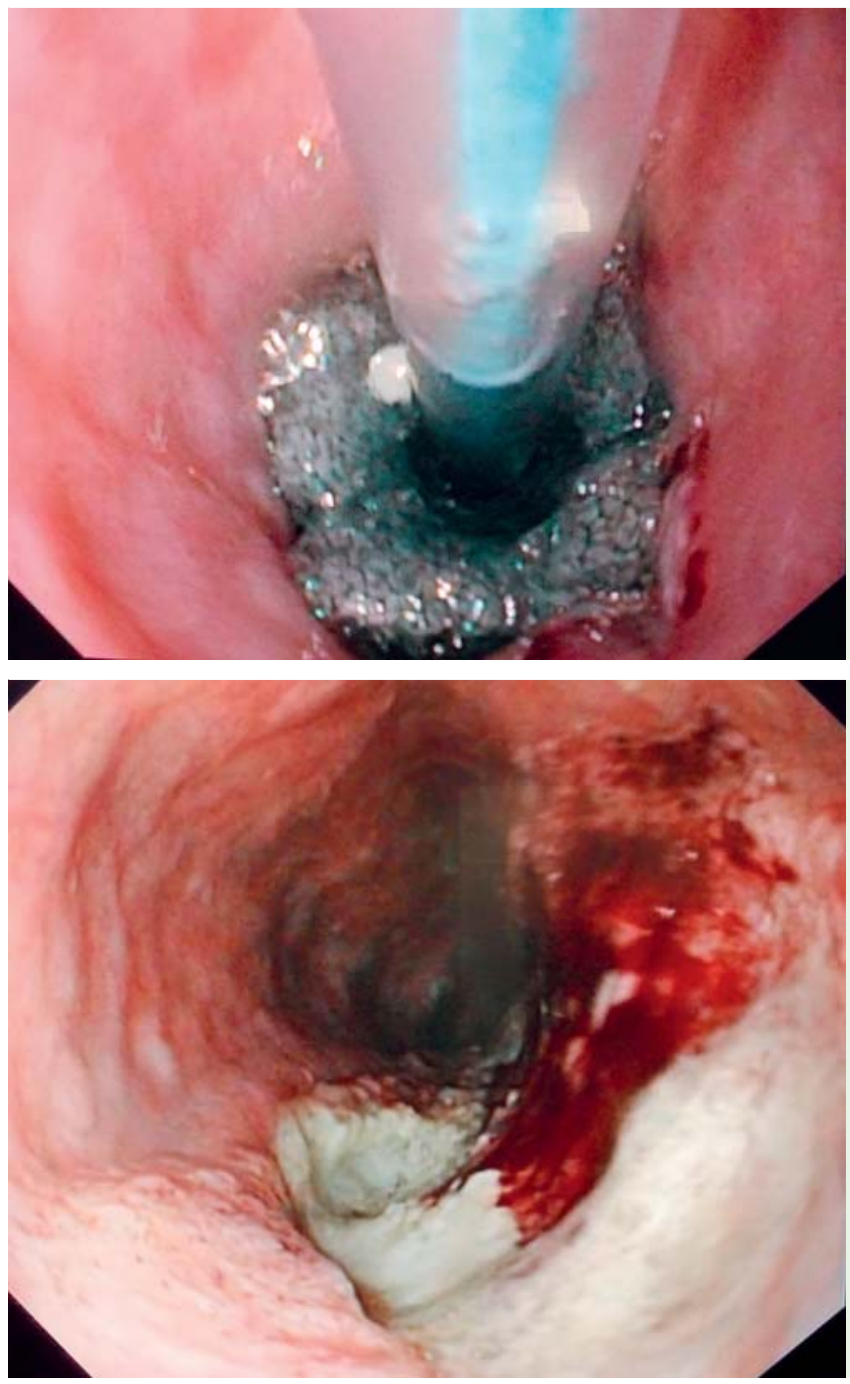

Esophageal perforation is a feared side effect of pneumatic dilation. Mediastinitis and consecutive sepsis are potentially lifethreatening complications. Endoscopic therapy using an endoluminal vacuumassisted closure system is a new method of treatment for esophageal leakage.

We present the case of a 65-year-old woman who was referred to us from an affiliated hospital with acute esophageal perforation following pneumatic dilation. Dilation had been performed earlier on the same day for diffuse esophageal spasm that did not respond to conservative treatment.

Endoscopy revealed a large rupture of the thoracic esophagus, ranging from $22 \mathrm{~cm}$ to $35 \mathrm{~cm}$ from the upper incisor teeth with complete perforation from $24-30 \mathrm{~cm}$ ( $\bullet$ Fig. 1). A polyurethane sponge (Renasys F; Smith \& Nephew, Hull, England) was trimmed and positioned intraluminally onto the site of the perforation via a guidewire (Amplatz Super Stiff guidewire; Boston Scientific, Natick, Massachusetts, USA) ( Fig. 2). A naso-esophageal drainage tube (Dahlhausen Medical, Köln, Germany), which had had additional perforations made to the tip, was also placed. Continuous suction (Redyrob Trans Plus wound drainage system; Aesculap AG, Tuttlingen, Germany) was applied via the drainage tube, which was fixed to the sponge using nonabsorbable suture material.

Prophylactic antibiotic treatment (cefixime and clindamycin) was initiated. Parenteral delivery of nutrition was changed to enteral nutrition after placement of a percutaneous gastric feeding tube.

Endoscopy check-up was performed on Day 3, and on Day 7 the sponge was changed ( Fig.3). The sponge was removed on Day 14, leaving a clean wound ground and fresh granulation tissue with good vascularization. Complete closure of the large esophageal defect was achieved (๑ Fig. 4 and $\bullet$ Fig. 5).

Inflammatory markers decreased continuously and were within the normal range at the time of sponge removal. The patient could be discharged from hospital on Day 20. Oral intake of fluid was possible by this time.

Oral nutrition was further increased to a solid diet over the subsequent weeks. Swallow function appeared to be better than before perforation; presumably, accidental disruption of esophageal wall muscle fibers led to alleviation of spasms. 


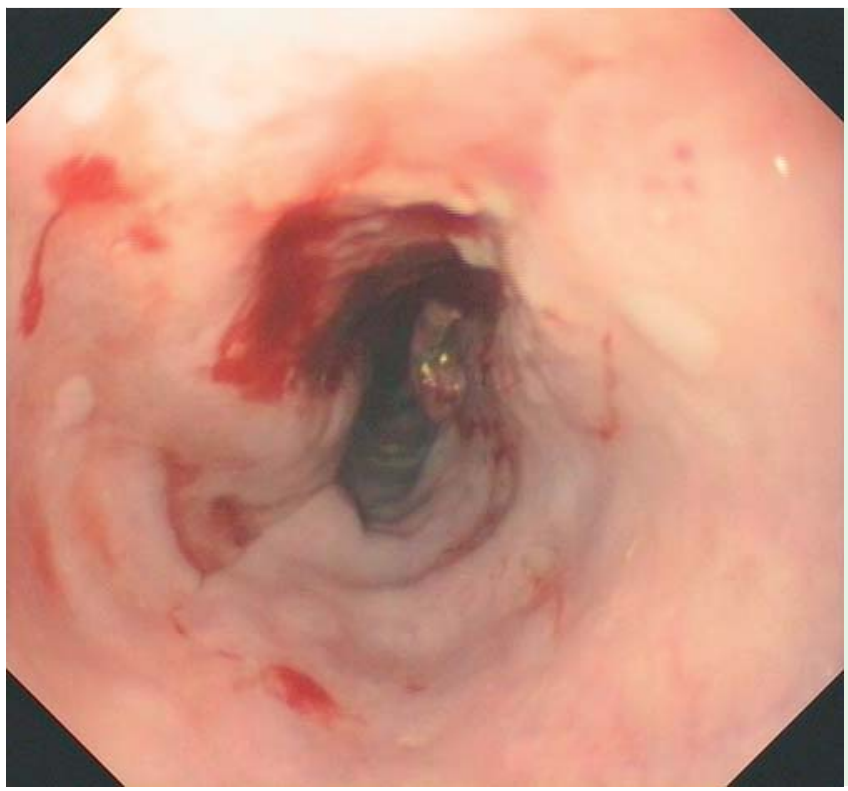

Fig. 4 Fresh granulation tissue, with good vascularization on Day 14.

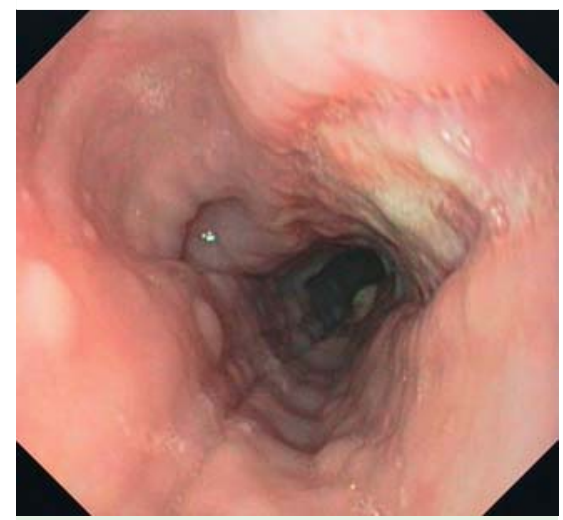

Fig. 5 Complete closure of the large esophageal defect on Day 18.

The present case supports the role of endoscopic therapy using an endoluminal vacuum-assisted closure system as a valuable option not only in the treatment of anastomotic leaks after esophageal surgery but also for traumatic esophageal lesions.

Endoscopy_UCTN_Code_TTT_1AT_2AD

Competing interests: None

\section{Holger Kronsbein', Markus Etzold', Martin Fein², Juergen Haverkock', Martin Steffen ${ }^{1}$}

${ }^{1}$ Klinik für Allgemeine Innere Medizin, Franziskus Hospital, Bielefeld, Germany

${ }^{2}$ Klinik für Allgemein-, Viszeral- und Gefäßchirurgie, Franziskus Hospital, Bielefeld, Germany
Bibliography

DOI http://dx.doi.org/

10.1055/s-0034-1377532

Endoscopy 2014; 46: E485-E486

(c) Georg Thieme Verlag KG

Stuttgart · New York

ISSN 0013-726X

Corresponding author

Holger Kronsbein, MD

Medizinische Klinik I

Franziskus Hospital

33615 Bielefeld

Germany

Fax: +49-521-5891104

holger.kronsbein@franziskus.de 